\title{
APLIKASI PERPUSTAKAAN MENGGUNAKAN PENDEKATAN CUSTOMER RELATIONSHIP MANAGEMENT (CRM) (STUDI KASUS SMPN 196 JAKARTA TIMUR)
}

\author{
Muhamad Irsan \\ Program Studi Teknik Informatika : Universitas Indraprasta PGRI \\ Email: atstairway@gmail.com
}

\begin{abstract}
Abstrak
Sistem perpustakaan yang dirancang untuk dapat dipergunakan secara langsung oleh para siswa dalam melakukan peminjaman buku. SMPN 196 terletak diwilayah Jakarta Timur. SMPN 196 saat ini belum mempunyai sistem perpustakaan yang digunakan untuk proses berbagai transaksi, termasuk proses peminjaman sampai dengan pengembalian atas peminjaman buku oleh para siswa. Sehingga dibutuhkan aplikasi desktop untuk fasilitas pembuatan order peminjaman buku atau pengembalian buku oleh para siswa. Penelitian ini merupakan Penelitian Terapan (Applied Research). Metode Pengumpulan data dilakukan dengan observasi langsung, studi pustaka dan dengan wawancara. Pengembangan model sistem perpustakaan ini ialah menggunakan pendekatan Customer Relationship Management (CRM). Pemodelan yang digunakan dalam menganalisa dan merancang sistem informasi ini adalah dengan pemodelan Analisis dan Perancangan Berorientasi Obyek (Object Oriented Analysis and Design) menggunakan Unified Modelling Language (UML). Pengujian validasi menggunakan Focus Group Discussion. Kualitas perangkat lunak yang dihasilkan diuji berdasarkan empat karakteristik kualitas perangkat lunak model ISO 9126, yaitu: functionality, reliability, usability, dan efficiency menggunakan metode kuesioner. Serta teknik pengujian perangkat lunak dengan Software Testing Webserver Stress Tool 7. Hasil yang diharapkan dalam Prototipe Sistem Desktop Perpustakaan ini mampu memberikan kontribusi terhadap SMPN 196 dan pelayanan kepada para siswa, sehingga dapat memperoleh informasi yang diinginkan dengan cepat dan akurat serta meningkatkan hubungan dengan para siswa.
\end{abstract}

Kata Kunci: Perpustakaan, Customer Relationship Management (CRM)

\begin{abstract}
A library system is designed to be directly used by students in borrowing books. SMPN 196 is located in East Jakarta. It doesn't have a library system that is used to process transactions, including the process of borrowing up to the returning of books by the students. Therefore, a desktop application is needed tofacilitatethe borrowing or returning of books by the students. This research is an Applied Research in whichdata are collected by direct observation, library research and interview methods. The library system model is developed using Customer Relationship Management (CRM) approach. The Modeling used to analyze and design the information system is Object-Oriented Analysis and Design with Unified Modeling Language (UML). Validation test applies Focus Group Discussion. The Quality of the resulted software is tested based on four characteristics of software quality model of ISO 9126: functionality, reliability, usability and efficiency, with a quisioner method and software testing technique using Software Testing Webserver Stress Tool 7. The Library Desktop System Prototype is expected to contribute to SMPN 196 and to service students, so that the desired information can be quickly and accurately obtained and the relationship with the students can be improved.
\end{abstract}

Keywords: Library, Customer Relationship Management (CRM), 


\section{Pendahuluan}

\section{Latar Belakang Masalah}

Pendidikan merupakan suatu usaha yang terencana untuk mewujudkan suasana belajar dan proses pembelajaran agar peserta didik secara aktif mengembangkan potensi dirinya untuk memiliki kekuatan spiritual keagamaan, pengendalian diri, kepribadian, kecerdasan, akhlak mulia, serta keterampilan yang diperlukan dirinya, masyarakat, bangsa dan negara.

Perpustakaan berkembang dengan pesat dan dinamis, sistem manualnya dirasakan tidak lagi memadai untuk penanganan beban kerja, khususnya kegiatan rutin dalam bidang pengadaan, pengatalogan, dan pengawasan sirkulasi. Perpustakaan merupakan suatu unit kerja yang berupa tempat mengumpulkan, menyimpan dan memelihara koleksi pustaka baik bukubuku ataupun bacaan lainnya yang diatur, diorganisasikan dan diadministrasikan dengan cara tertentu untuk memberi kemudahan dan digunakan secara kontinu oleh pemakainya sebagai informasi. Perpustakaan sekolah adalah suatu unit kerja dari sebuah lembaga persekolahan yang berupa tempat menyimpan koleksi bahan pustaka penunjang proses pendidikan yang diatur secara sistematis untuk digunakan secara berkesinambungan sebagai sumber informasi untuk memperkembangkan dan memperdalam pengetahuan, baik oleh pendidik maupun mereka yang dididik di sekolah tersebut.

Tujuan utama penyelenggaraan perpustakaan sekolah yakni meningkatkan mutu pendidikan bersama-sama dengan unsur-unsur sekolah lainnya. Adapun tujuan lainnya adalah menunjang, mendukung, dan melengkapi semua kegiatan baik kurikuler, ko-kurikuler dan ekstra kurikuler, di samping dimaksudkan pula dapat membantu menumbuhkan minat dan mengembangkan bakat murid serta memantapkan strategi belajar mengajar.

\section{Hipotesis}

Dari kerangka konsep yang telah disusun oleh penulis maka pernyataan penelitian ini dapat dirumuskan sebagai berikut :

1. Diduga model analisis, perancangan dan implementasi dari perangkat lunak Prototipe perpustakaan menggunakan Pendekatan Customer Relationship Management (CRM)

2. Pada SMPN 196 dapat memberikan kontribusi terhadap sekolah dalam memberikan fasilitas terbaik terhadap para siswa.

3. Diduga kualitas perangkat lunak Prototipe perpustakaan menggunakan pendekatan Customer Relationship Management pada SMPN 196 yang dihasilkan jika diukur berdasarkan kualitas perangkat lunak dengan ISO 1926 adalah baik. Dan dari hasil pengujian perangkat lunak Software Testing adalah baik.

\section{Tinjauan Pustaka}

Perpustakaan dalam Kamus Besar Bahasa Indonesia berasal dari kata dasar pustaka yang memiliki arti kitab, buku. Dalam bahasa Yunani, perpustakaan disebut dengan Biblia, artinya tentang buku, kitab. Dalam bahasa Belanda nama lain dari perpustakaan yakni Bibliotecha. Sedangkan dalam bahasa Inggris perpustakaan dikenal dengan istilah Library yang diambil dari kata dasarnya yaitu Librer atau Libri yang artinya adalah buku.

Menurut Peraturan Menteri Pendidikan Nasional No. 25 Tahun 2008, menyatakan bahwa perpustakaan merupakan unit kerja yang memiliki sumber daya manusia sekurangkurangnya seorang pustakawan, ruangan atau tempat khusus, dan koleksi bahan pustakaan sekurang-kurangnya seribu judul dari berbagai disiplin ilmu yang sesuai dengan jenis dan misi perpustakaan yang bersangkutan serta dikelola menurut sistem tertentu untuk kepentingan masyarakat penggunanya.

Sedangkan menurut Dian Sinaga (2007:29), “perpustakaan merupakan pusat informasi yang menyediakan beragam pengetahuan dan informasi bagi penggunanya. Layanan diberikan 
dengan dasar kesamaan akses bagi setiap orang tanpa membedakan umur, ras, agama, kebangsaan, jenis kelamin maupun status sosial".

Secara umum dapat disimpulkan bahwa pengertian perustakaan adalah suatu institusi unit kerja yang menyimpan koleksi bahan pustaka secara sistematis dan mengelolanya dengan cara khusus sebagai sumber informasi dan dapat digunakan oleh pemakainya.

1. Syamsul Robi (2005) melakukan penelitian dalam skipsinya dengan judul "Perancangan Sistem Informasi Perpustakaan berbasis komputerarisasi pada SMA YMIK II Jakarta", melakukan penelitian terhadap aplikasi perpustakaan sekolah mencakup data anggota dan data buku, yang bertujuan untu mempermudah dan mengelola data anggota dan data buku perpustakaan yang terdapat di SMA YMIK II Jakarta agar pekerjaan menjadi efektif dan efisien serta membantu menyelesaikan permasalahan pekerjaan yang berkenaan dengan pengelolaan data, agar dapat terselesaikan dengan tepat waktu. Dalam tugas akhirnya beliau mengguanakan bahasa pemograman Borland Delphi 7.0 serta Microsoft Access.

2. Damayanti (2005) melakukan penelitian dalam skipsinya dengan judul " perancangan sistem informasi perpustakaan pada SMP IGNATIUS SLAMET RIYADI", melakukan penelitian terhadap aplikasi perpustakaan sekolah mencakup data anggota dan data buku, yang bertujuan system informasi pada SMP IGNATIUS SLAMET RIYADI lebih efektif serta memaksimalkan proses pencarian buku, pendaftaran anggota baru, peminjaman buku, pengembalian buku sampai pembuatan laporan yang dilakukan setiap akhir tahun.

\section{Metodologi Penelitian}

Proses pengembangan sistem seringkali menggunakan pendekatan prototipe (prototyping). Metode ini sangat baik digunakan untuk menyelesesaikan masalah kesalahpahaman antara pengguna dan analis yang timbul akibat user tidak mampu mendefinisikan secara jelas kebutuhannya (Mulyanto, 2009).

Prototyping adalah pengembangan yang cepat dan pengujian terhadap model kerja (prototipe) dari aplikasi baru melalui proses interaksi dan berulang-ulang yang biasa digunakan ahli system informasi dan ahli bisnis. Prototyping disebut juga desain aplikasi cepat (rapid application design / RAD) karena menyederhanakan dan mempercepat desain sistem (O'Brien, 2005).

Sebagian user kesulitan mengungkapkan keinginannya untuk mendapatkan aplikasi yang sesuai dengan kebutuhannya. Kesulitan ini yang perlu diselesaikan oleh analis dengan memahami kebutuhan user dan menerjemahkannya ke dalam bentuk model (prototipe). Model ini selanjutnya diperbaiki secara terus menerus sampai sesuai dengan kebutuhan user (Mulyanto, 2009).

Keunggulan prototyping (Mulyanto, 2009) adalah :

1. Adanya komunikasi yang baik antara pengembang dan pelanggan.

2. Pengembang dapat bekerja lebih baik dalam menentukan kebutuhan pelanggan.

3. Pelanggan berperan aktif dalam pengembangan sistem.

4. Lebih menghemat waktu dalam pengembangan sistem.

5. Penerapan menjadi lebih mudah karena pemakai mengetahui apa yang diharapkannya.

Sedangkan kelemahan prototyping (Mulyanto, 2009) adalah :

1. Pelanggan tidak melihat bahwa perangkat lunak belum mencerminkan kualitas perangkat lunak secara keseluruhan dan belum memikirkan peneliharaan dalam jangka waktu yang lama.

2. Pengembang biasanya ingin cepat menyelesaikan proyek sehingga menggunakan algoritma dan bahasa pemrograman sederhana.

3. Hubungan pelanggan dengan komputer mungkin tidak menggambarkan teknik perancangan yang baik. 
Pengembangan dari perancangan sistem ini penulis dalam pelaksanaanya menggunakan tiga tahap siklus pengembangan model prototipe, yaitu :

1. Mendengarkan pelanggan. Merupakan tahap pertama dalam merancang sebuah sistem. Pada tahap ini akan menentukan informasi-informasi yang dibutuhkan oleh pelanggan agar tercipta sebua aplikasi sehingga mengarah pada tujuan dibuatnya aplikasi tersebut.

2. Membangun dan Memperbaiki Prototipe. Dalam tahap ini dilakukan perancangan dan pengkodean untuk sistem yang diusulkan yang mana tahapanya meliputi perancangan proses-proses yang akan terjadi didalam sistem, perancangan diagam UML yang akan digunakan, perancangan antar muka keluara serta dilakukan tahap pengkodean terhadap rancangan-rancangan yang telah didefinisikan, kelengkapan software dan hardware.

Pengujian Prototipe. Pada tahapan ini dilakukan pengujian ISO 9126 terhadap sistem yang telah disusun dan melakukan pengenalan terhadap sistem yang telah diujikan serta evaluasi apakah sistem yang sudah jadi sudah sesuai dengan yang diharapkan.

\section{Langkah-langkah Penelitian}

Berikut adalah langkah-langkah penelitian yang ditempuh oleh penulis untuk membangun prototipe aplikasi desktop perpustakaan menggunakan pendekatan Customer Relationship Management (CRM).

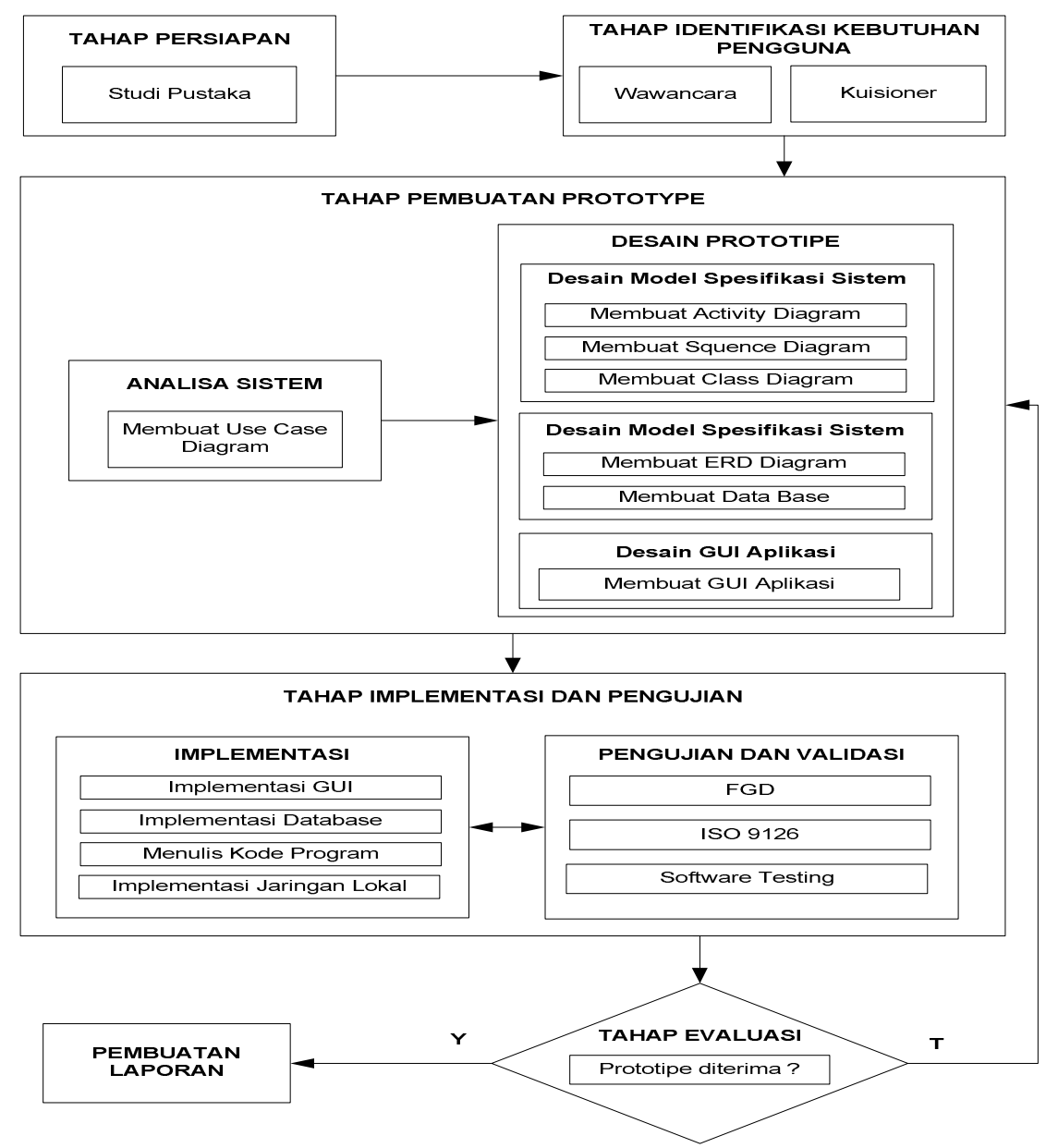

\section{Gambar 1. Langkah-langkah Penelitian}

Berikut adalah penjelasan dari langkah-langkah penelitian diatas :

1. Tahap Persiapan. Pada tahap ini dilakukan dengan mempelajari literatur yang berkaitan dengan e-customer order, sistem informasi manajemen, Prototype Evolusioner, PHP, webservice, kualitas perangkat lunak model ISO 9126, dan 
pengujian sistem. Dalam tahapan inijuga dilakukan studi dan analisa dari beberapa penelitian sebelumnya, berupa jurnal nasional maupun tesisliteratur lainnya mengenai prototipe sistem perpustakaan dengan pendekatan CRM.

2. Tahap Identifikasi Kebutuhan Pengguna. Pada tahap ini ialah dilakukan identifikasi kebutuhan pengguna dengan cara melakukan observasi dan wawancara dengan Kepala Sekolah, Staff Admin Perpustakaan dan customer (dalam hal ini siswa) terkait untuk mempelajari kebutuhan pengguna dan kebutuhan sistem.

3. Tahap Pembuatan Prototipe. Dari pengumpulan data, pada tahap ini akan dilakukan analisa kebutuhan pengguna, kebutuhan fungsional dan non-fungsional sistem serta analisa perilaku sistem. Pemodelan yang dilakukan dalam tahapan analisis ini adalah:

a. Pembuatan use case diagram untuk memodelkan kebutuhan fungsional dan pengguna.

b. Pembuatan activity diagram dan sequence diagram. Activity diagram untuk memodelkan proses use case yang berjalan di dalam sistem. Sequence diagram untuk memodelkan pengiriman pesan (message) antar object dan kronologinya.

Berdasarkan hasil analisis, kemudian dilanjutkan dengan melakukan perancangan sistem untuk menggambarkan bagaimana sistem dapat memenuhi kebutuhan yang sudah ditetapkan, dengan melakukan prosedur-prosedur berikut:
a. Pembuatan pemodelan.
b. Perancangan antarmuka (input, output, dan navigasi)
c. Perancangan arsitektur.
d. Perancangan konseptual basis data.

4. Tahap Implementasi dan Pengujian. Pada tahap ini juga dilakukan implementasi kode program (coding) berdasarkan hasil analisis dan perancangan sistem kedalam bahasa pemograman yang digunakan berupa aplikasi berbasis web yang akan dikoneksikan dengan webservice dan MySQL database. Langkah-langkah pengkodean mencakup sumber daya yang digunakan, database, pembuatan rancangan input dan output, sistem menu dan membuat panduan penggunaan aplikasi, agar aplikasi lebih mudah dipahami oleh pengguna.

Pengujian yang pertama untuk memvalidasi fungsi perangkat lunak berdasarkan spesifikasi kebutuhan yang sudah dianalisis dan dirancang, meliputi pengujian fungsionalitas sistem dan fungsi penyediaan data dan informasikan oleh eksekutif. Pengujian ini dilaksanakan dengan menggunakan metode Focus Group Discussion(FGD).

Pengujian yang kedua dilakukan untuk menguji tingkat kualitas perangkat lunak yang dikembangkan dengan standarisasi empat karakteristik ISO 9126.

Pengujian selanjutnya dengan menggunakan dengan software testing yaitu Webserver Stress Tool 7 untuk mengetahui kinerja sistem apabila diuji dengan perangkat yang berbeda dan masalah atau bugs yang terjadi selama pengujian.

5. Tahapan Evaluasi. Pada tahap ini peneliti melakukan evaluasi seluruh fungsi dan hasil pengujian dan implementasi prototipe, jika dari hasil evaluasi tidak sesuai dengan kebutuhan yang sudah di indentifikasi pada tahap no 2. Maka peneliti harus mengulang proses pembuatan prototipe dari awal kembali sesuai dengan metode prototipe evolusioner. Apabila hasil evaluasi menyatakan prototipe dapat di terima dan di pakai, maka penulis dapat melanjutkan pembuatan laporan.

6. Pembuatan Laporan. Pada tahap ini tahap akhir dalam penelitian, maka peneliti membuat laporan akhir hasil dari evaluasi dan pengujian. 


\section{Hasil dan Pembahasan}

\section{Analisa Sistem dengan Pendekatan Customer Relationship Management (CRM)}

Didalam proses analisis sistem dengan pendekatan Customer Relationship Management (CRM) ialah mendeskripsikan apa yang harus dilakukan oleh sistem guna memenuhi kebutuhan informasi pengguna dan memberikan peyanan kepada customer. Analisis sistem akan menjawab pertanyaan apa yang akan dikerjakan oleh sistem, siapa yang akan menggunakan sistem, dan dimana serta kapan sistem tersebut akan digunakan. Kegiatan dari analisis sistem yang dirancang ialah dengan melakukan pendekatan analisis berorientasi objek, hal ini dimaksudkan untuk menitik beratkan kepada fungsionalitas sistem tersebut. Peneliti dalam hal ini juga menggunakan pendekatan metode Top-Down dalam menganalisa kebutuhan pengguna untuk pembuatan prototipe ini. Selanjutnya dari hasil analisis akan divisualisasikan dan didokumentasikan dengan Unified Modelling Language (UML) melalui Use Case Diagram, Activity Diagram, dan Sequence Diagram dengan pertimbangan bahwa diagram tersebut dapat mewakili secara keseluruhan sistem yang dibuat dan dapat dimengerti oleh pengguna.

\section{Analisa Kebutuhan Fungsional dan Non Fungsional}

Setelah melakukan observasi dan wawancara terhadap pihak sekolah dan para siswa, peneliti mengalami kendala karena banyaknya permintaan fitur yang di minta oleh manajemen dan para siswa dalam prototipe ini. Namun peneliti melakukan proses elisitasi terhadap kebutuhan fungsional dan non fungsional agar di dapatkan beberapa kebutuhan yang sebenarnya dibutuhkan oleh pengguna.

Kebutuhan-kebutuhan tersebut adalah sebagai berikut :

Elisitasi Tahap 1

Berisi seluruh permintaan melalui wawancara dengan pihak manajemen dan customer yang akan menjadi dasar rancangan prototipe sistem yang akan dikembangkan.

Tabel 1. Elisitasi Functional \& Nonfunctional

\begin{tabular}{|c|c|}
\hline \multicolumn{2}{|c|}{ Functional } \\
\hline \multicolumn{2}{|c|}{ User ingin sistem : } \\
\hline 1 & $\begin{array}{l}\text { Dapat di akses oleh seluruh staff karyawan } \\
\text { sekolah dalam satu menu. }\end{array}$ \\
\hline 2 & $\begin{array}{l}\text { Dapat di akses oleh para siswa dalam satu } \\
\text { menu. }\end{array}$ \\
\hline 3 & $\begin{array}{l}\text { Dapat menampilkan menu order peminjaman } \\
\text { buku. }\end{array}$ \\
\hline 4 & $\begin{array}{l}\text { Dapat menampilkan menu input/edit/delete } \\
\text { order peminjaman buku. }\end{array}$ \\
\hline 5 & $\begin{array}{l}\text { Dapat menampilkan menu Lihat Data } \\
\text { Peminjam. }\end{array}$ \\
\hline 6 & $\begin{array}{l}\text { Dapat menampilkan history peminjam secara } \\
\text { keseluruhan. }\end{array}$ \\
\hline 7 & $\begin{array}{l}\text { Dapat menampilkan data peminjam yang } \\
\text { belum diverifikasi. }\end{array}$ \\
\hline 8 & $\begin{array}{l}\text { Dapat menampilkan data peminjam yang } \\
\text { sudah diverifikasi. }\end{array}$ \\
\hline 9 & $\begin{array}{l}\text { Dapat menampilkan menu view Karyawan } \\
\text { Perpustakaan. }\end{array}$ \\
\hline 10 & $\begin{array}{ll}\text { Dapat menampilkan menu } & \text { registrasi } \\
\text { Karyawan dan Siswa untuk login. } & \end{array}$ \\
\hline 11 & $\begin{array}{l}\text { Dapat menampilkan menu input/edit/delete } \\
\text { siswa untuk login. }\end{array}$ \\
\hline 12 & $\begin{array}{l}\text { Tersedia fungsi tambah pengguna pada menu } \\
\text { pengaturan }\end{array}$ \\
\hline
\end{tabular}




\begin{tabular}{ll}
\hline NonFunctional \\
\hline Saya ingin sistem dapat : \\
\hline 1 & Menampilkan halaman login untuk Karyawan \\
2 & Menampilkan halaman login untuk Sswa \\
3 & Menampilkan pesan jika salah penginputan \\
4 & Menampilkan cara pemakaian aplikasi \\
5 & Hanya membutuhkan kurang 3 menit untuk \\
& login aplikasi. \\
\hline
\end{tabular}

Use Case

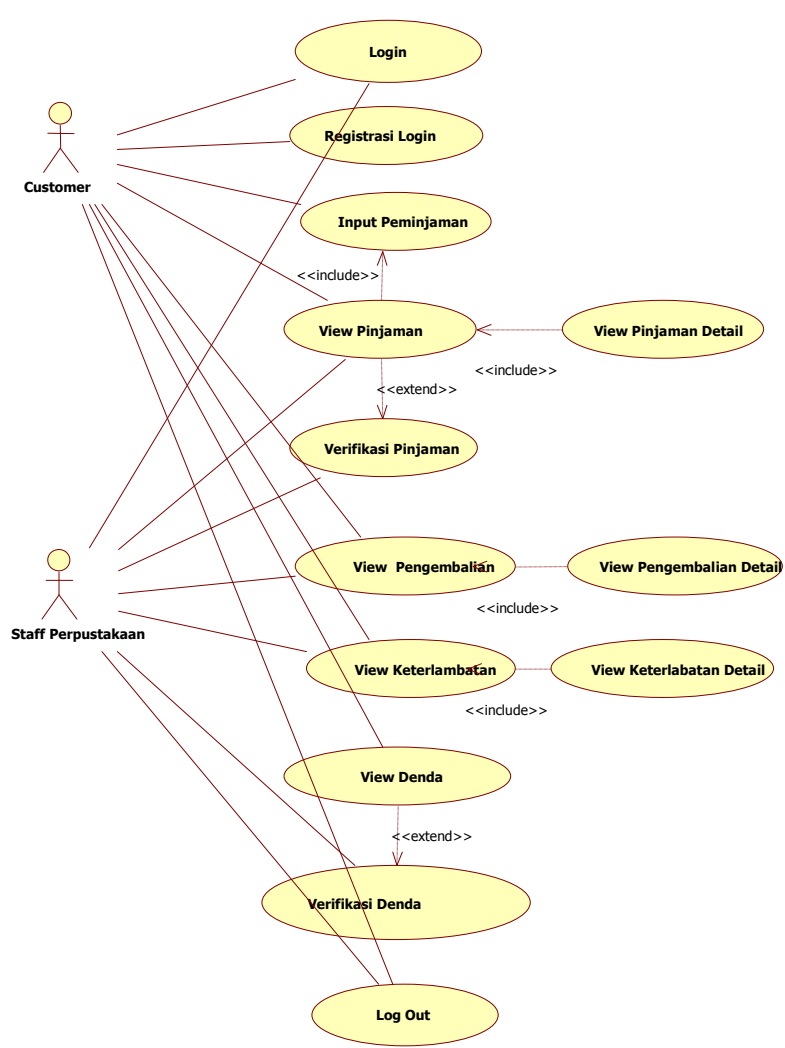

Gambar 2. Use Case Diagram 


\section{Activity Diagram Menu Login}

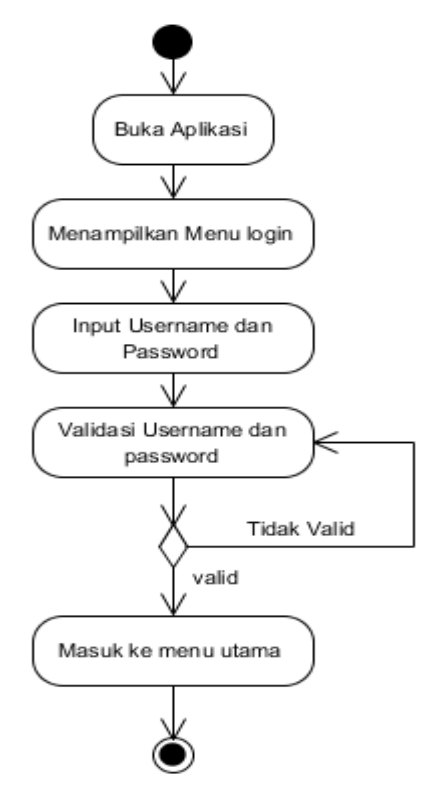

\section{Gambar 3. Activity Diagram Login Menu}

Deskripsi Activity Diagram Login:

1) Pengguna membuka sistem. Pengguna disini adalah Staff karyawan Perpustakaan.

2) Sistem akan menampilkan form login.

3) Pengguna memasukkan User ID dan Password.

4) Sistem akan memvalidasi User ID dan Password, jika tidak valid, maka sistem akan meminta untuk memasukkan kembali user ID dan Password.

5) Jika User ID dan Password sudah valid maka pengguna langsung masuk ke menu utama.

Sequence Diagram Menu Login :

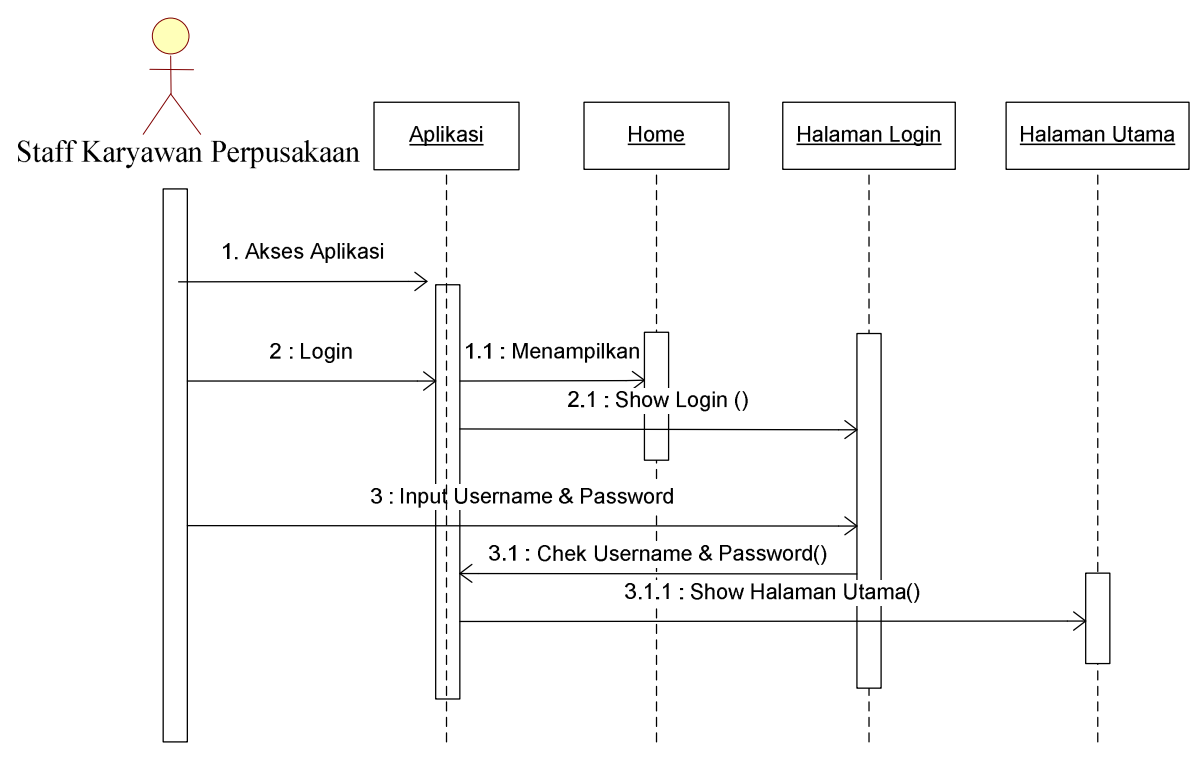

Gambar 4. Sequence Diagram Login Menu 


\section{Sequence Diagram Input Peminjaman :}

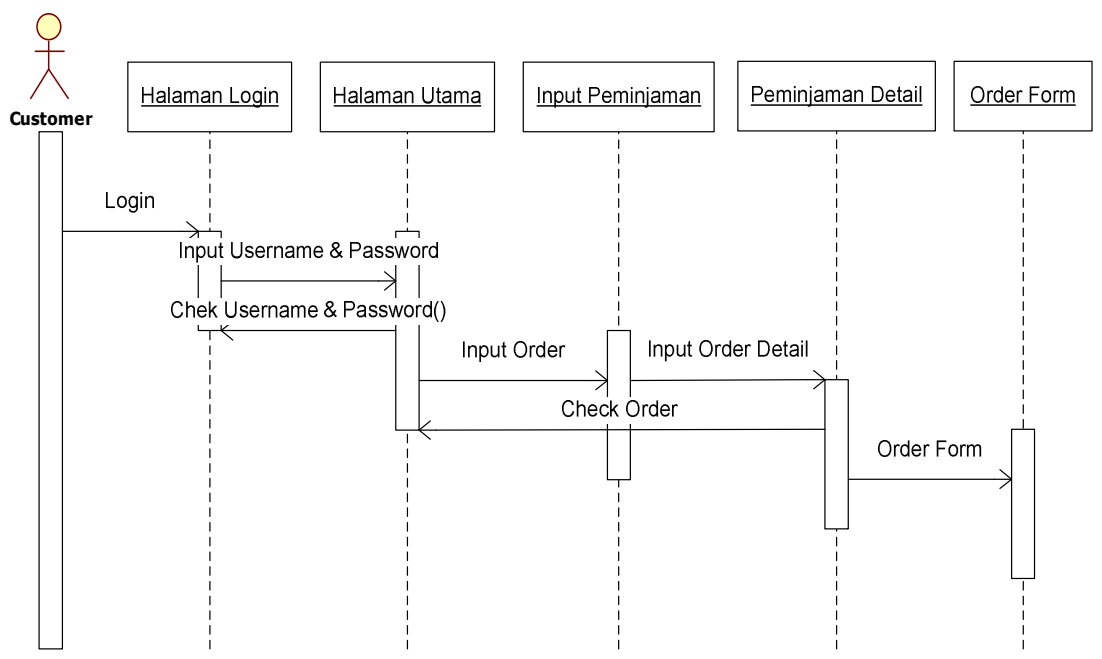

Gambar 5. Sequence Diagram Menampilkan Hasil Perhitungan

\section{Pengujian dengan ISO 9126}

Pengujian kualitas sistem menggunakan ISO 9126 ini terdiri dari 2 bagian, yaitu: tingkat kualitas masing-masing aspek berdasarkan empat karakteristik ISO 9126, dan tingkat kualitas secara keseluruhan dari empat karakteristik ISO 9126. Dari 10 responden yang mengisi kuesioner untuk pengujian kualitas perangkat lunak prototipe aplikasi perpustakaan. Tanggapan responden terhadap tingkat kualitas prototipe sistem informasi berdasarkan jawaban responden terhadap indikator kualitas software menurut ISO 9126, dapat diukur dengan menggunakan rumus sebagai berikut :

$$
\% \text { Skor Aktual }=\frac{\text { SkorAktual }}{\text { SkorIdeal }} \times 100 \%
$$

\section{Hasil Pengujian Kualitas}

Dari beberapa pengujian yang di lakukan dengan criteria ISO 9126 maka hasil yang di dapatkan dapat di lihat pada tabel berikut :

Tabel 2. Hasil Pengujian Kualitas

\begin{tabular}{ccccc}
\hline \multirow{2}{*}{ Aspek } & $\begin{array}{c}\text { Skor } \\
\text { Aktual }\end{array}$ & $\begin{array}{c}\text { Skor } \\
\text { Ideal }\end{array}$ & $\begin{array}{c}\text { \% Skor } \\
\text { Aktual }\end{array}$ & Kriteria \\
\hline Functionality & 215 & 250 & $86.00 \%$ & Sangat Baik \\
Reliability & 130 & 150 & $86.67 \%$ & Sangat Baik \\
Usability & 172 & 200 & $86.00 \%$ & Sangat Baik \\
Efficiency & 86 & 100 & $86.00 \%$ & Sangat Baik \\
\hline Total & $\mathbf{6 0 3}$ & $\mathbf{7 0 0}$ & $\mathbf{8 6 . 1 7 \%}$ & Sangat Baik \\
\hline
\end{tabular}




\section{Simpulan dan Saran}

Berdasarkan dari penelitian yang dilakukan penulis terkait dengan Aplikasi Perpustakaan dapat disimpulkan:

1. Prototipe Aplikasi Perpustakaan dapat diintegrasikan menggunakan penerapan Customer Relationship Management (CRM) sesuai dengan pengguna yakni mempunyai bentuk menu yang mudah dipahami, kontras dengan warna, tampilan menu menggunakan ikon dan tulisan, perhitungan langsung serta dapat menggantikan pekerjaan manual.

2. Aplikasi Perpustakaan menggunakan kuesioner model ISO 9126 ini dapat memberikan kepuasan kepada pengguna pada aplikasi perpustakaan.

3. Aplikasi Perpustakaan menggunakan pendekatan Customer Relationship Management $(C R M)$ dapat memberikan hasil yang akurat kepada pengguna dalam memberikan informasi. Aplikasi Perpustakaan menggunakan pendekatan Customer Relationship Management (CRM) dapat meningkatkan pelayanan dan hubungan kinerja semakin harmonis antara karyawan dan para siswa.

Dari hasil penelitian dan kesimpulan yang penulis lakukan, maka penulis memberikan saran untuk perusahaan dan penelitian lebih lanjut, yaitu :

A. Untuk Pihak Sekolah

1. Apabila aplikasi sistem informasi perpustakaan ini diterapkan maka harus ada sosialisasi dan pelatihan kepada semua user baik dari karyawan maupun para siswa.

2. Apabila aplikasi sistem informasi perpustakaan ini diterapkan perlu adanya security sistem dan maintenance sistem secara berkala karena sistem ini diintegrasikan dengan jaringan.

B. Untuk Peneliti Selanjutnya

1. Untuk peneliti selanjutnya, dapat mengembangkan sistem informasi perpustakaan lebih baik lagi dengan berbasis mobile dan yang lainnya.

2. Perlu dilakukan penelitian lebih lanjut dari segi efisiensi dan efektifitas pada rancangan Sistem Informasi perpustakaan menggunakan pendekatan CWM maupun yang lainnya.

\section{Daftar Pustaka}

Damayanti. (2005). Perancangan Sistem Informasi Perpustakaan pada SMP IGNATIUS SLAMET RIYADI. Yogyakarta: AMIKOM.

Kamus Besar Bahasa Indonesia http://bahasa.kemdiknas.go.id/kbbi/index.php. Diakses 16 November 2016.

Mulyanto, A. (2009). Sistem Informasi Konsep dan Aplikasi. Yogyakarta: Pustaka Pelajar.

O'Brien, J.A. (2005). Introduction to Information System. 12th Edition. New York: McGraw Hill Companies Inc.

Robi, S. (2005). Perancangan Sistem Informasi Perpustakaan berbasis komputerarisasi pada SMA YMIK II Jakarta. Surabaya : Universitas Airlangga.

Sinaga, D. (2007). Mengelola Perpustakaan Sekolah. Jakarta: Kreasi Media Utama.

Supriyanto, A. (2008). Pengantar Teknologi Informasi. Jakarta: Salemba Infotek. 